Derecho y Realidad

Vol. 13 - Núm.26 • Julio-Diciembre de2015

Págs. 207-234 • ISSN: 1692-3936

\title{
Condiciones para el desarrollo del derecho a la alimentación como derecho fundamental ${ }^{\star}$
}

\author{
Conditions for the development of the right to \\ feeding as fundamental right
}

\author{
Mauricio Betancourt García**
}

\section{Resumen}

En el presente escrito se hace un estudio del desarrollo del derecho a la alimentación y de las temáticas que atañen a él, contextualizando las condiciones sociales, de concentración de la riqueza en el mundo, y los problemas de subalimentación existentes. Se trabaja la relación entre derecho a una alimentación adecuada y los derechos fundamentales. Otro aspecto relaciona los elementos teóricos y jurídicos que sustenta el DAA, partiendo de los derechos subjetivos, los inalienables, los metaderechos, los derechos fundamentales, el concepto del mínimo vital, el compromiso que significa el derecho internacional consuetudinario y los derechos económicos. También se trabaja sobre las obligaciones internacionales que han firmado los países latinoamericanos y las formas constitucionales y de políticas que tienen para resolver este DAA de las poblaciones, finalmente se alude a una parte de la situación colombiana.

Fecha de aceptación: 2 de agosto de 2015

Concepto de recepción: 10 de agosto de 2015

Fecha de aprobación: 15 de septiembre de 2015

* Ponencia presentada en el Encuentro de Derechos Humanos de la Facultad de Derecho de la Universidad Pedagógica y Tecnológica de Colombia, Tunja octubre de 2015.

** Profesor titular de la Escuela Superior de Administración Pública, coordinador Proyección Social Maestría en Gestión Urbana de la UPC. Bogotá Colombia. 


\section{Palabras clave}

Derecho a los alimentos, estado, subalimentación, derecho internacional consuetudinario, derechos fundamentales, economía.

\section{A bstract}

This document presents a study of the development of the right to food and the subjects that occupy it, contextualization of social conditions, the concentration of wealth in the world, and the problems existing And existing problems of undernourishment. The relationship between the right to adequate food and the fundamental rights work. Another aspect relates the theoretical and legal elements supporting the DAA, based on subjective rights, inalienable, the metarights, fundamental rights, the concept of vital minimum commitment involved in customary international law and economic rights It also works on international obligations that have signed Latin American countries and the constitutional and political forms that have to solve this DAA populations, finally it referred to a part of the Colombian situation.

\section{Keywords}

Right to food; state; undernourishment; customary international law; fundamental rights; economy.

\section{Sumario}

1. Introducción

2. Contexto económico y social global y la necesidad de cumplir el DAA

3. DAA y su relación con los derechos fundamentales

4. Los componentes jurídicos del DAA

5. Las obligaciones legales internacionales y las regulaciones constitucionales del DAA

6. La situación en Colombia

7. Conclusiones

8. Referencias Bibliográficas

\section{Metodología}

Se elabora un texto reflexivo que propone explorar las principales problemáticas del derecho a la alimentación con el ánimo de establecer un análisis de la interacción de aspectos jurídicos, económicos, legales y espaciales, que orienten una visión más clara del derecho a la alimentación. 
"Si consideramos que el derecho a los alimentos tiene tanta importancia como los otros derechos humanos, debemos tomar las medidas necesarias para su aplicación, con más razón cuando hemos comenzado a perseguir los crímenes por genocidio (...) La existencia del hambre es, lisa y llanamente, una injusticia".

(Hauenstein \& Vaitla, 2007, p. 30)

\section{Introducción}

Esta ponencia trabaja cinco aspectos sobre el derecho a una alimentación adecuada (DAA). La primera, contextualiza las condiciones sociales, de concentración de la riqueza en el mundo, y los problemas de subalimentación existentes. Luego se trabaja la relación entre derecho a una alimentación adecuada y los derechos fundamentales. El tercer aspecto relaciona los elementos teóricos y jurídicos que sustenta el DAA, partiendo de los derechos subjetivos, los inalienables, los metaderechos, los derechos fundamentales, el concepto del mínimo vital, el compromiso que significa el derecho internacional consuetudinario y los derechos económicos. También se trabaja sobre las obligaciones internacionales que han firmado los países latinoamericanos y las formas constitucionales y de políticas que tienen para resolver este DAA de las poblaciones. Por último se alude a una parte de la situación colombiana.

\section{Contexto económico y social global y la necesidad de cumplir el DAA}

La argumentación del derecho a la alimentación parte de las dinámicas y de las necesidades humanas en el contexto local, regional, nacional y global, como un hecho social que exige soluciones de parte del Estado y la sociedad. Una de las primeras condiciones sociales que vincula la obligación moral y jurídica de este derecho, se presenta cuando vemos las grandes desigualdades sociales existentes en el capitalismo contemporáneo, en la medida que afecta la cadena alimentaria, en la fase de acceso, al respecto Oxfam (citado por Caetano \& De Armas, 2015) afirma que:

(...) el año pasado el $1 \%$ más rico del planeta era dueño del 48 por ciento de la riqueza del mundo. Pero las tendencias tienden a agravarse: en el 2016 ese 1\% tendrá más del 50\% y en el 2019 más del 54\%. Si desagregáramos los grandes segmentos, nos encontraremos con asimetrías incluso más irritantes: en el 2014, el $20 \%$ del $99 \%$ concentraba el $46.5 \%$ de ese restante 52, al tiempo que las ochenta personas más ricas del planeta poseen actualmente lo mismo que los 3.600 millones de personas más pobres. En ese contexto escandaloso, la situación de América Latina, a pesar de haber mejorado en la última década, sigue manteniendo guarismos muy preocupantes. Según el 
Banco Mundial y el Centro de Estudios Distributivos, Laborales y Sociales (CEDLAS), América Latina es la segunda región más desigual del planeta (52,9 de coeficiente de Gini), apenas por debajo del África Subsahariana $(56,5)$ y seguida desde bastante lejos por Asia $(44,7)$ y por Europa del Este y Asia Central (34,7). (Caetano \& De Armas, 2015) (Negrillas fuera de texto)

En esta dirección, el análisis sobre el desarrollo en las últimas décadas en América Latina resalta las condiciones de la urbanización, sustentada a partir de las proyecciones demográficas del Celade de la Cepal, las cuales muestran que: "el ímpetu del proceso de urbanización. El impulso no se detuvo ni siquiera a finales del siglo XX, con la década perdida y su secuela de efectos adversos sobre las ciudades, y tampoco en el siglo XXI" (Cepal \& Celade, 2013, p. 18), pero surge la pregunta ¿por qué no se detuvo este proceso?, dadas las circunstancias de las formas de vida de las ciudades, con la migración y posterior redistribución territorial de la población en los centros urbanos, la ONU-Hábitat, encontraban en América Latina que:

Las ciudades de la región, vistas en su conjunto, son y se mantienen como las más inequitativas del planeta. Pese a los avances económicos y las iniciativas para combatir la pobreza, no ha habido mejoras significativas en materia de equidad. Las ciudades latinoamericanas y del Caribe son ciudades "duales", "divididas", "segregadas", algo que se expresa tanto espacial como socialmente. (ONU- Hábitat, 2012, p. XIII)

Estas condiciones de concentración de la riqueza y de segregación espacial y social, conlleva a pensar las políticas públicas en cumplimiento del DAA, en el contexto de las necesidades de la población latinoamericana, ya que la Cepal reconocía en el 2014:

(...) la tasa de pobreza de América Latina en 2013 fue de un 28,1\% de la población, en tanto que la indigencia, o pobreza extrema, alcanzó el 11,7\%. Estos porcentajes equivalen a 165 millones de personas en situación de pobreza, de los cuales 69 millones son personas en situación de pobreza extrema (Cepal, 2014, pág. 64)

Por tanto, la Cepal confirmaba su pronosticó de 2002, como un elemento estructural y característico de la región desde los años 80, "la gran mayoría de los latinoamericanos vive en países en los que la desigualdad en la distribución del ingreso registró un aumento en el último cuarto del siglo XX" (Cepal, 2002, p. 85 ), estas condiciones estructurales consideran la urgente necesidad de políticas vinculadas a procesos de desarrollo regional y local que contribuyan a mejorar las condiciones de pobreza de América Latina, las cuales deben permitir el cumplimiento 
del DAA, que tengan en cuenta algunos mínimos de desarrollo a partir de integrar políticas entre los gobiernos nacionales y subnacionales, desde los requerimientos nutricionales de las poblaciones en cada uno de los territorios y el principio de la disponibilidad de la comida cerca de la mesa, lo que implica relaciones internacionales entre iguales en un contexto globalizador.

Globalmente, la Tabla 1 muestra la población en el mundo en condiciones de desnutrición, desde 1990 hasta el 2014, destacando que la globalización con todos los adelantos tecnológicos ha logrado disminuir en 24 años solo 209 millones de personas, y que las poblaciones que se encuentran en estado de inseguridad alimentaria, hoy hay 805 millones, al ritmo del último cuarto de siglo necesitamos casi un siglo para resolver la situación de desnutrición en el mundo, esto sin contar que aparezcan nuevas personas, por consiguiente surge la pregunta, ¿cuál debe ser la forma operativa para cumplir desde los diferentes Estados el DAA para sus poblaciones?, pues ya no solamente está referido a las regiones en desarrollo que han avanzado dinámicamente más que los desarrollados, excepto África y Oceanía.

Hay que tener en cuenta que los diferentes Estados han asumido desde 1948 dos declaraciones importantes, en orden de jerarquía internacional, una, en París con la ONU, donde se firma la Declaración Universal de los Derechos Humanos, que considera, en su artículo 25: “Toda persona tiene derecho a un nivel de vida adecuado que le asegure, así como a su familia, la salud y el bienestar, y en especial la alimentación, el vestido, la vivienda, la asistencia médica y los servicios sociales necesarios". Y otra, en Bogotá, aprobada en medio de la Novena Conferencia Internacional Americana con la OEA, la Declaración Americana de los Derechos y Deberes del Hombre, en su artículo 11 sobre: "Derecho a la preservación de la salud y al bienestar. Toda persona tiene derecho a que su salud sea preservada por medidas sanitarias y sociales, relativas a la alimentación, el vestido, la vivienda y la asistencia médica, correspondientes al nivel que permitan los recursos públicos y los de la comunidad". Con estas dos declaraciones, la Defensoría del Pueblo de Colombia considera que:

(...) ambos instrumentos consagran normas y principios del derecho internacional consuetudinario que son de obligatorio cumplimiento por los Estados y que, por tanto, resultan relevantes para definir y concretar el contenido normativo del derecho a la alimentación. (Gómez, 2006, p 35)

Por consiguiente, tenemos los instrumentos legales para organizar el DAA, sin embargo, encontramos estas situaciones expresadas en el mundo actual, que riñen con este derecho. 
La pregunta pertinente ante la persistencia y continuidad de esta situación es: ¿En cuánto tiempo, con que arreglos institucionales, con qué instrumentos y montos financieros, con que voluntades políticas subnacionales, nacionales y globales se necesitan con el fin de resolver este flagelo de la humanidad?

Tabla 1. La subalimentación en el mundo, 1990-92 a 2012-14

\begin{tabular}{|c|c|c|c|c|}
\hline \multicolumn{5}{|c|}{$\begin{array}{c}\text { Cuadro No. } 1 \text { La subalimentación en el mundo, } \\
1990-92 \text { a 2012-14 }\end{array}$} \\
\hline \multirow{3}{*}{$\begin{array}{l}\text { Regiones del } \\
\text { mundo }\end{array}$} & \multicolumn{4}{|c|}{$\begin{array}{c}\text { Número (millones) de personas subalimentadas } \\
\text { y prevalencia }(\%) \text { de la subalimentación }\end{array}$} \\
\hline & \multicolumn{2}{|c|}{ 1990-92 } & \multicolumn{2}{|c|}{$2012-14^{*}$} \\
\hline & N. ${ }^{\circ}$ & $\%$ & N.o & $\%$ \\
\hline MUNDO & 1014,5 & 18,7 & 805,3 & 11,3 \\
\hline $\begin{array}{l}\text { REGIONES } \\
\text { DESARROLLADAS }\end{array}$ & 20,4 & $<5$ & 14,6 & $<5$ \\
\hline $\begin{array}{l}\text { REGIONES EN } \\
\text { DESARROLLO }\end{array}$ & 994,1 & 23,4 & 790,7 & 13,5 \\
\hline África & 182,1 & 27,7 & 226,7 & 20,5 \\
\hline $\begin{array}{c}\text { América Latina } \\
\text { y el Caribe }\end{array}$ & 68,5 & 15,3 & 37 & 6,1 \\
\hline Asia & 742,6 & 23,7 & 525,6 & 12,7 \\
\hline Oceanía & 1.0 & 15,7 & 1,4 & 14.0 \\
\hline \multicolumn{5}{|c|}{$\begin{array}{l}\text { * Previsiones. Fuente: FAO, FIDA y PMA. 2014. El estado de la inseguridad } \\
\text { alimentaria en el mundo } 2014 \text {. Fortalecimiento de un entorno favorable para la } \\
\text { seguridad alimentaria y la nutrición. Roma, Cuadro } 1 .\end{array}$} \\
\hline
\end{tabular}

\section{DAA y su relación con los derechos fundamentales}

Un acercamiento a la definición del DAA lo explicita la ONU en los siguientes términos:

El derecho a la alimentación es el derecho a tener acceso, de manera regular, permanente y libre, sea directamente, sea mediante compra en dinero, a una alimentación cuantitativa y cualitativamente adecuada y suficiente, que corresponda a las tradiciones culturales de la población a que pertenece el consumidor y que garantice una vida psíquica y física, individual y colectiva, libre de angustias, satisfactoria y digna (ONU, 2005, p. 5)

Un concepto y contexto sobre la Seguridad Alimentaria Nutricional -SAN-, es el derecho de los seres humanos a tener alimentos para la vida, y en este sentido se vincula directamente con los derechos fundamentales; en la medida que la determinación de la estructura de los derechos sociales fundamentales, debe crear las condiciones que permitan igualdad y libertad; "los derechos sociales fundamentales son derechos del individuo frente al Estado en demanda de acciones fácticas positivas" (Arango, 2005, p. 113), que relacionan las exigencias de los titulares, o sea, quienes no tienen acceso a los alimentos. 
Por tanto, hay una serie de elementos que determinan la necesidad de exigir en el mundo actual DAA, como un derecho fundamental que se vincula con las posibilidades de vivir con dignidad así: "Todos los hombres, mujeres y niños tienen el derecho inalienable a no padecer hambre" (FAO, 1974), por tanto, al no asegurarse el derecho a la alimentación adecuada ${ }^{1}$ a un número creciente de personas, que por diferentes razones no pueden acceder a éste, la sociedad y el Estado en especial tiene una gran responsabilidad en esta situación, de tal manera que sobre este último recae la responsabilidad de dar cumplimiento a este derecho.

Este derecho está incluido en los derechos conocidos como de segunda generación, los cuales "empezaron a ser reivindicados a finales del siglo XIX; son los derechos económicos, sociales y culturales que (...) exigen de cuantiosos medios económicos para garantizarlos, y por ello solo podrán satisfacerse gradualmente de acuerdo al momento histórico y a las posibilidades de cada estado" (Medina, 2006, p. 3), exigen voluntad política para su aplicación, cuando los recursos públicos cuantiosos se dirigen hacia sectores que no tienen carencias fundamentales ni en los que la vida digna está en peligro.

Esta vinculación conlleva a la existencia de otros derechos que son complementarios y conexos con el DAA, como es el derecho al agua, el cual se vincula como un derecho humano, a partir de su definición que busca:

(...) garantizar a cada ser humano una cantidad mínima de agua de buena calidad y suficiente para la vida y la salud; es decir, que permita satisfacer necesidades esenciales como la bebida, la preparación de alimentos, la higiene y la producción de cultivos de subsistencia (...) En el núcleo del derecho al agua reside el principio de que nadie puede ser privado de la cantidad suficiente de agua para satisfacer sus necesidades fundamentales (...) el derecho al agua hace parte de los derechos fundamentales (Molina, 2005, p. 17 y ss)

En este sentido, las condiciones para cumplir con el DAA son contextuales e integrales, con otros derechos que hacen parte fundamental de la vida de las poblaciones.

\footnotetext{
Al respecto de la discusión sobre este derecho, tenemos que este ha cambiado, cuando los fundamentos sobre los cuales se sustenta el concepto de seguridad alimentaria supera el componente típicamente económico; hoy encontramos que están "todos los elementos de la seguridad alimentaria, incluida la disponibilidad, accesibilidad y utilización de los alimentos, pero trasciende el concepto de seguridad alimentaria porque se hace hincapié en la rendición de cuentas. El enfoque basado en los derechos hace hincapié en el hecho de que progresar para reducir el porcentaje de personas hambrientas constituye una obligación jurídica, no solamente una preferencia o una elección" (Ziegler, 2002); por tanto, ahora, este cambio en la obligación centra la discusión sobre la seguridad alimentaria en el terreno imperativo de las políticas públicas, hacia la solución de un problema de ética humana.
} 


\section{Los componentes jurídicos del DAA}

Los ejes de la discusión sobre este derecho, pasan por revisar en el derecho mismo los componentes generales que lo sustentan como son: los derechos subjetivos, los derechos inalienables, los derechos de trasfondo e institucionales, los derechos sociales fundamentales, y los derechos económicos familiares (SEN), estos diferentes manejos sobre derechos teóricos, permiten sustentar sus acciones a través de las organizaciones públicas, privadas y sociales; y de las diversas legislaciones de tipo internacional, nacional, departamental, regional, distrital, municipal y local para su aplicación.

Sin embargo, en este contexto, aparece una responsabilidad moral individual y colectiva frente a los informes y las políticas sobre el hambre nacionales y globales, dado que, por un lado va el proceso de construcción de la argumentación jurídica, y por el otro el desfase entre estos elementos de tipo conceptual, normativo, las políticas públicas y la moral individual y colectiva, frente a las condiciones y los casos de muertes por inanición en un mundo.

\section{Los derechos subjetivos}

Estos adquieren individualizaciones a partir del derecho privado, en la medida que la coerción permite su aplicación y demanda su ejecución, quedando en cabeza de los individuos y las responsabilidades del Estado. Para Kant (citado por Habermas),

su teoría del derecho de derechos subjetivos naturales que otorgan a toda persona la capacidad de ejercer coerción contra las vulneraciones de sus libertades de acción, que esos derechos aseguran. Con el tránsito del derecho natural al derecho positivo esas facultades de ejercer coerción, las cuales, tras la monopolización ejercida de todos los medios de coerción legítima por parte del Estado ya no pueden ser ejercitadas directamente por las personas jurídicas particulares, se convierten en facultades de ejercer una acción o demanda. (Habermas, 1998, p. 90)

Lo cual sintetiza las posibilidades de la realización de los derechos de los individuos que, al no asegurarse, vulneran sus "libertades de acción", y los convierten en potenciales demandantes de derechos y encabezando un Estado para ser demandado ante su incumplimiento.

Con las nuevas dimensiones y competencias del Estado, bajo los modelos actuales, cambian las responsabilidades de los diferentes sujetos, dado que, con

el derecho moderno opera un desplazamiento por lo que antes se exigía normativamente de los individuos, los cuales de este modo quedan por así 
decir, moralmente exonerados, se transforma en exigencias que ahora se hacen a las leyes, las cuales han de asegurar la compatibilidad de las libertades de acción. Estas reciben legitimidad de un procedimiento legislativo que se apoya a su vez en el principio de soberanía popular. Con ayuda de los derechos que aseguran a los ciudadanos el ejercicio de su autonomía política ha de poder explicarse el paradójico surgimiento de la legitimidad a partir de la legalidad. (Habermas, 1998, p. 148), (negrillas fuera de texto).

En consecuencia, nos encontramos con un vínculo fundamental para la realización de los derechos, al combinar las libertades de acción con el aseguramiento de los ciudadanos para poder ejercer su autonomía política a partir de asegurar sus derechos, pero además en este punto se ha avanzado para no dejar solo en manos del Estado esta responsabilidad la cual también recae sobre el individuo, la familia y las empresas.

Es en esta dirección que Habermas relaciona los derechos ciudadanos al justificar la vinculación de los derechos subjetivos como condición de igualdad frente a la libertad, reconociendo que se tiene un derecho subjetivo

cuando el orden jurídico deja al implicado la realización de un fin reconocido, es decir, la satisfacción de un interés reconocido, y para tal propósito le dota de un poder jurídico -en síntesis un derecho de interés reconocido que permite un poder jurídico, y que está en el mismo nivel que los derechos civiles y políticos y en este sentido lo define como- una facultad jurídica, conferida al individuo por el orden jurídico, y por su fin un medio para la satisfacción de intereses humanos. (Habermas, 1998, p. 151)

Desde esta óptica, el derecho subjetivo, para satisfacer intereses humanos, permite el reconocimiento no solo del que legisla, sino del que posee el deber de hacerlo cumplir en función de las libertades individuales y colectivas.

Las bases anteriores sobre los derechos subjetivos son puntualizadas por Arango, al considerar que:

(...tienen el sentido de descargar a las personas jurídicas los preceptos morales bien determinados concediendo a los actores espacios legales para las acciones guiadas por sus propias preferencias (...) Los derechos subjetivos con los que se construye el ordenamiento jurídico moderno tiene el sentido de dispensar a las personas jurídicas de las obligaciones morales. Con la introducción de los derechos subjetivos, que otorgan a los actores un espacio de acción en el que actuar conforme a sus propias preferencias, el derecho moderno hace valer el principio general de que está permitido todo lo que no está explícitamente prohibido. (Arango, 2005, p. 28) 
De esta manera se sustenta el ingreso de los individuos a lo que se llaman titulaciones de derechos, y en este sentido son responsabilidades mutuas frente al Estado. Por tanto, encontramos que hay "el poder legal reconocido a un sujeto por medio de una norma legal, para la persecución de intereses propios, mediante la exigencia a otro de hacer, permitir, u omitir algo -lo cual lleva a entender el derecho subjetivo caracterizado por-(i) una norma jurídica (M1), (ii) una obligación jurídica (M2) de otro derivada de esta norma, y (iii) un poder jurídico (M3) para la consecución de intereses propios reconocidos al sujeto (es decir, una posición jurídica) (Maurer, citado por Arango, 2005, p. 9). En estas condiciones se puntualizan los componentes que deben existir cuando nos encontramos operando los derechos subjetivos, al tener elementos para su aplicación como derechos sociales fundamentales que se expresan en normas, obligaciones y poderes jurídicos, los cuales permiten la acción de la política pública formal y la estructuración de acciones en dirección a solucionar $\mathrm{y}$ atender el DAA.

\section{Los derechos inalienables}

Estos derechos son la base que integra derechos subjetivos e irrenunciabilidad de derechos, al permitir el desarrollo de las libertades individuales, cuya definición sustenta que: "para justificar la existencia de derechos inalienables debe demostrarse que ciertos derechos establecen entre sus presuntos titulares y un bien una relación que estos individuos no pueden romper" (Meyers, 1988, p. 24). Este punto relaciona individuos, colectivos y Estado, o titulares de derechos y responsables de la aplicación, sin que unos y otros se desprendan de sus deberes y responsabilidades.

Diana Meyers considera cuatro derechos inalienables como parte central sobre los cuales se permite lograr:

(...) un objetivo elemental en los sistemas morales, estos derechos son: 1. El derecho a la vida; 2 . La libertad personal; 3 . Al buen trato; y 4. A la satisfacción de las necesidades básicas; frente a estos derechos, no se puede renunciar (...) por razones de conciencia (Meyers, 1988, p. 59)².

Estos son derechos a los cuales se debe responder para su aplicación a través de diferentes tipos de acciones desde los responsables de su protección, y los cuales son imperativos morales y políticos en cualquier sociedad actual.

$2 \quad$ No nos vamos a ocupar de la discusión sobre la irrenunciabilidad de los derechos, ya que lo que nos interesa en términos del trabajo es la sustentación del derecho a la alimentación como base de acción de las políticas públicas. Este tema es tratado de forma extensa en el texto citado de Diana Meyers (1988). 
El cuarto derecho inalienable, considera que debe disponer "de comida adecuada, agua, ropa, vivienda, cuidados médicos para sobrevivir y protección ante cierto tipo de privaciones -por supuesto su no satisfacción, que conlleva a los titulares de éste- a causar dolor y por tanto deteriorar la acción moral (...) si estas carencias no se solucionan pueden ir acumulándose y matar a la persona que las sufre, y por tanto destruir la acción moral exactamente igual que si se tratase de una violación del derecho a la vida. Es importante destacar que este derecho lo que busca es paliar la fragilidad humana proporcionándole ciertos bienes que ningún otro derecho garantiza" (Meyers, 1988, p. 68 y ss.), (negrillas fuera de texto). El estar en este mundo, lo hace titular de un derecho irrenunciable y exigible, y al cual la sociedad, las empresas y el Estado deben responder como atenuante moral.

En el anterior sentido, el derecho a la tierra se integra a esta situación vital, en la medida que,

la tierra es un recurso vital para la mayoría de las comunidades rurales, no solo para la realización de sus derechos económicos, sociales y culturales (alimentación, vivienda, trabajo, vida cultural), sino también para el goce de los derechos civiles y políticos(a la vida, a ser libre de servidumbre, a la protección judicial, a la participación política). (Monsalve, 2004, p. 41)

Por tanto, para muchas de las poblaciones campesinas, indígenas y afrodescendientes de las zonas rurales, la posibilidad de tener acceso a los alimentos, pasa por la tenencia y el derecho a la tierra, como uno de los elementos que tienen de producir alimentos para su sustento, y acceder a unas mejores condiciones de vida. Por esto, Monsalve concluye:

Si bien no hay un derecho humano a la tierra, el derecho a la tierra de las comunidades rurales está implícito en otros derechos humanos recogidos en los tratados internacionales: derecho a la propiedad, a la libre determinación, a la vida cultural de las minorías étnicas y a un nivel adecuado de vida. (Monsalve, 2004, p. 55)

Por su parte, los informes de la FIAN Internacional, confirman las necesidades de las relaciones entre el derecho a la tierra y el DAA. En el Informe R 1 consideraba:

Las $\mathrm{DV}^{3}$ también urgen a los Estados que hayan establecido el derecho a una alimentación adecuada en sus sistemas legales a informar al público en general

3 DV - Directrices Voluntarias en Apoyo de la Realización Progresiva del Derecho a la Alimentación Adecuada en el Contexto de la Seguridad Alimentaria Nacional. 
de todos los derechos y vías de recurso disponibles (...) la disponibilidad directa de alimentos a través de la propia cultivación de la tierra es parte del contenido básico del derecho a la alimentación adecuada para los individuos y los grupos rurales que así quieran ejercer su derecho (Monsalve, s.f., p. 5 y ss.)

Los derechos inalienables ubican la discusión sobre el tipo de moral que puede tener una sociedad en cierto momento, por tanto, "las personas tienen derechos inalienables porque los sistemas morales no pueden autoanularse ni autorrescindirse, o porque los sistemas morales deben apoyar la acción moral" (Meyers, 1988, p. 113), y por supuesto, el hambre, la malnutrición y muerte por falta de acceso a una alimentación acorde y necesaria, pone en conflicto diferentes valores con la moral individual y social.

Las observaciones de Vernon sobre hasta dónde el hambre plantea problemas morales en la opinión pública y desde cuándo se convirtieron en problema de esta opinión:

Hoy en día, estamos tan familiarizados con el terrible espectáculo de gente muriendo de hambre en algún territorio lejano que nos cuesta imaginar una época en la que la inanición no era noticia y en la que los hambrientos apenas suscitaban compasión (...) el hambre se convirtió en noticia por primera vez durante los años cuarenta del siglo XIX, pero hasta las últimas décadas del siglo, no se estableció firmemente como una causa humanitaria (...) ligado a diferentes objetos y causas desde finales del siglo XVIII, fue que se centró en el sufrimiento de gente desconocida (Vernon, 2011, p. 31)

Amartya Sen, frente a este problema, considera que parece que hoy conviviera un tipo de moral que acepta esta situación para millones de seres humanos, por lo que se hace más grave el problema:

Lo que hace que este extendido el problema del hambre sea una tragedia aún mayor es el hecho de que hayamos acabado aceptándolo y tolerándolo como si constituyera una parte fundamental del mundo moderno, como si fuera una tragedia imposible de evitar (Sen, 2000, p. 250)

La unión entre moral y derecho internacional frente al DAA, como un derecho inalienable, se vincula no solo con los territorios sobre los cuales se asume esta responsabilidad, o se implementan acciones públicas, hoy este derecho no solo es un problema de las naciones individualmente, sino que responsabiliza también la comunidad internacional, en la medida que "las fronteras nacionales no subdividen a la comunidad de agentes morales a menos que establezcan barreras para tal acción" (Meyers, 1988, p. 164). En dicho sentido, se salvarían de responsabilidades 
frente a los derechos las naciones ricas $^{4}$ y llevarían la peor parte las naciones pobres, lo que lleva a preguntarse, ¿cuáles deben de ser las acciones de los Estados en esta perspectiva?, la cual se podría ejecutar a través de una política pública, para poblaciones específicamente identificadas, en los territorios locales.

La aplicación de los derechos inalienables hoy tiene una pregunta: ¿Quién o quiénes deben ser los responsables de lograr que estos derechos se desarrollen y se cumplan? Los individuos, la familia, las empresas, la sociedad a través de sus diversas formas de organización o el Estado como representante de esta, lo cual requiere antes de su decisión, que

Si los derechos a la asistencia y ayuda se respetan, todos los que necesitan ayuda deben ser identificados, el coste que esto supone debe ser repartido proporcionalmente a la riqueza de los que lo pagan y las formas más adecuadas de ayuda deben ser proporcionadas a los que realmente lo necesitan. Sin la participación de las instituciones públicas, la satisfacción de estas necesidades está sujeta a multitud de avatares. (Meyers, 1988, p. 163)

Lo que implica construir una metodología que identifique los diferentes niveles de intervención y relaciones entre los mismos, en el momento del desarrollo de las acciones.

\section{Los metaderechos}

Este concepto es planteado por SEN, así: "un metaderecho a algo X puede ser definido como el derecho a tener políticas $\mathrm{p}(\mathrm{X})$ que persigan genuinamente el objetivo de hacer realizable el derecho a X" (Sen, 2002, p. 15). Este planteamiento relaciona la identidad del derecho con la responsabilidad de verlo realizado a través de acciones, lo cual desemboca en los metaderechos. Sen llega a este análisis buscando responder la pregunta “ ¿Tienen las personas derecho a estar libres de hambre?"

Con la anterior pregunta, Sen inicia la discusión entre derechos y metaderechos. Y teniendo en cuenta los conceptos sobre los que trabaja Dworkin (Sen, 2002, p. 14), referidos a los derechos de: trasfondo, los cuales justifican las decisiones políticas; los institucionales, que proveen la institución específica para X decisión; los abstractos, como objetivos generales sin ponderación frente a otros objetivos políticos; los concretos, como objetivos específicos priorizados.

$4 \quad$ Hoy ni siquiera estas naciones se salvan, pues persisten más de 14 millones de seres humanos en estado de desnutrición en estos países. 
En esta dirección es que Sen considera que:

(...) el metaderecho a ser liberado del hambre es el derecho a tal política pero que en últimas está tras ese derecho objetivo de alcanzar es la libertad (Sen, 2002, p. 16)

Por tanto, el fin último del metaderecho a no tener hambre, vincula la posibilidad y el poder de ser libre. También entre la consecución de la libertad se encuentra el desarrollo y la expansión de "las libertades fundamentales para el enriquecimiento de la vida humana (...) se encuentran algunas capacidades elementales como, por ejemplo poder evitar privaciones como la inanición, la desnutrición, la morbilidad evitable y la mortalidad prematura" (Sen, 2000, p. 55) los cuales, conjugados con otras condiciones permitirían, la "expansión de las libertades humanas", en este sentido se entendería en Sen, las relaciones entre derecho a la alimentación y metaderechos, los cuales se vinculan con la libertad y el desarrollo, sustentando su justificación en las funciones sociales e individuales que se consideran cuando hay desarrollo.

Por otra parte, Arango considera que el concepto de metaderecho de Sen cumple tres funciones centrales en la discusión sobre los derechos:

1. De transformación categorial: acerca del discurso de los objetivos políticos y el discurso de los derechos; 2. De control político: ofrece una propuesta para exigir la política necesaria para hacer posible la realización de los derechos positivos; 3. De responsabilidad política conecta la responsabilidad política del legislador y su control público - political accountability- frente a la toma de medidas necesarias para la realización de los derechos positivos (Sen, El Derecho a no Tener Hambre, 2002, p. 9).

Si se quiere desde el ángulo de los metaderechos encontramos un acercamiento general a justificar la necesidad de una política de SAN acorde con las necesidades de las personas independientes de ubicación en la sociedad y en el mundo, ya también con acciones integrales a partir de los controles sobre las acciones públicas que afecten este metaderecho.

\section{Los derechos fundamentales}

Identificados como "los derechos del individuo frente al Estado en demanda de acciones fácticas positivas" (Arango, 2005, p. 113); y en este sentido, se vinculan con otros conceptos más generales sobre los derechos, como son los existentes entre derechos subjetivos, inalienables y metaderechos. 
Por consiguiente la determinación de la estructura de los derechos sociales fundamentales, debe entonces crear las condiciones que permitan dignidad ${ }^{5}$, igualdad, y libertad; las cuales se relacionan con las exigencias de los titulares, quienes no tienen acceso a los alimentos de manera continua, ya que existe la necesidad, y aunque exista la norma, la obligación, el poder y la posición jurídica, los individuos y las comunidades carecen en muchos espacios del DAA.

Determinar el objeto de estos derechos, plantea dificultades, particularmente en la ejecución de las acciones ordenadas por las políticas públicas, y en las coordinaciones entre los diferentes niveles de gobierno:

(...) un problema de reconocimiento, el cual no debe resolverse a favor de fines funcionales o de razones organizativas del Estado (mediante la resolución de conflictos de competencias), sino en beneficio de los derechos fundamentales del individuo; ello porque los derechos fundamentales vinculan a todos los organismos estatales y exigen de éstos contribuir decididamente a su realización (Arango, 2005, p. 111).

Esta anotación de Arango, aclara que se requieren acciones de forma integral expresadas en las políticas públicas de los diferentes niveles que tienen los gobiernos en Colombia, lo que implica un criterio de racionalidad del gasto público del estado en su solución, y un trabajo de integralidad real de las acciones y los gastos públicos, sobre los territorios priorizados como más graves, donde los derechos fundamentales entre ellos el de la alimentación se comporten como eje de las acciones sociales prioritarias del Estado y del gobierno en cualquiera de sus niveles.

\section{El mínimo vital}

Este concepto, desarrollado como derecho innominado ${ }^{6}$, presenta entonces varias aristas relacionales con otros derechos conexos; uno es su definición, que inicia sustentada por la sentencia de la Corte Constitucional T 426/92 "La persona requiere

5 Frente a la dignidad humana, Pérez se pregunta: “¿Qué entendemos por dignidad humana, jurídicamente hablando? Y la respuesta es: En derecho, la dignidad humana lo es, sencillamente, todo (...) en tal medida, apreciándola como fuente conceptual de donde nacen valores jurídicos superiores como la libertad, la igualdad, la solidaridad o fraternidad, que son los que sientan las bases de un sistema de convivencia y organización social (derecho), hasta tomarla como supuesto teórico de una serie de derechos fundamentales". (Pérez, 2011, p. 83)

6 "para la Corte Constitucional -en Colombia- el derecho al mínimo vital es un derecho fundamental innominado (...) los jueces constitucionales reconocen los derechos fundamentales innominados a partir de una concepción holista de la Constitución" (Arango \& Lemaitre, 2002, p. 11). En lo fundamental, este punto se desarrolla a partir de consultas de decisiones de la Corte Constitucional $y$ de este texto. 
de un mínimo de elementos materiales para subsistir. La consagración de derechos fundamentales en la Constitución busca garantizar las condiciones económicas y espirituales necesarias para la dignificación de la persona humana y el libre desarrollo de su personalidad", y posteriormente se puntualizó como:

(...) aquella suma estrictamente necesaria para cubrir las necesidades básicas de alimentación, educación, vestuario, vivienda, sin la cual es prácticamente imposible lograr el objeto constitucional enunciado dentro de los postulados del Estado Social de Derecho. (Corte Constitucional de Colombia, Sentencia T 1006 de 1999)

En este sentido, se determina que al Estado social de derecho se le exige esforzarse en la construcción de las condiciones indispensables para asegurar a todos los habitantes del país una vida digna dentro de las posibilidades económicas que estén a su alcance, partiendo de las mínimas condiciones para su seguridad material.

Bajo los anteriores parámetros de la Corte Constitucional de Colombia, se considera que el mínimo vital parte de un concepto donde

los derechos fundamentales que incluyen en determinadas circunstancias a los derechos sociales como derechos justiciables. Detrás de ello, está una teoría de la justicia como justicia distributiva, en particular una concepción de la justicia distributiva a partir de las capacidades actuales del individuo (Arango, 2002, p. 64).

Lo que exige una determinación de políticas públicas que apunten en la solución de un problema central de la seguridad alimentaria, a partir del mínimo vital, para la población independiente del sector social y territorial al cual pertenece, solo requiere de condiciones de vulnerabilidad social.

Por su parte, Pérez caracteriza el mínimo vital, como:

(...) un derecho de creación o, en términos más exactos de deducción jurisprudencial, teniendo en cuenta que se extrae de la interpretación sistemática de varias disposiciones constitucionales. (Pérez, 2011, p. 25)

\section{El derecho internacional consuetudinario}

Un aspecto central del este derecho es que tienen un carácter vinculante y es considerado por Carrillo, así: "una generalización de la práctica de los Estados, es decir, la prueba de un consenso general de expectativas generalmente aceptadas como derecho o, si se prefiere, la cristalización de un consenso de los Estados 
respecto a una determinada pauta de comportamiento que se impone como derecho objetivo" (Carrillo, 2006, p. 34); son acuerdos, pactos y declaraciones internacionales consensuadas por los diferentes Estados y en este sentido se convierten en puntos vinculantes para determinar acciones públicas de orden nacional y regional.

Por tanto, el derecho internacional consuetudinario, es una obligación jurídica aplicable en el nivel nacional y de carácter obligatorio para los Estados firmantes, en este punto hay que resaltar el papel que juega el derecho en el actual contexto internacional, donde encontramos un "pluralismo jurídico", de De Sousa Santos, quien considera que en las condiciones contemporáneas este "tiene que ver con la idea de que más de un sistema jurídico opera en una misma unidad política" (De Sousa Santos, 1998, p. 24). Bajo estos criterios ¿cuáles son las normas que se aplican en el territorio donde se encuentran los dueños de las titulaciones del hambre?; y en este sentido se vuelve más imperativo las acciones que de forma integral se realizan, por parte de los distintos niveles de gobierno nacional, departamental, municipal y local, los otros Estados y gobiernos, las organizaciones globales y la cooperación internacional.

En esta dirección hay unas obligaciones a partir de existir un bloque de constitucionalidad en el Estado, el cual está referidos para permitir: "el contenido normativo de diversos tratados internacionales ratificados por Colombia, entre los que se hallan aquellos que definen, regulan el contenido, las obligaciones y procedimientos en torno al derecho a la alimentación" (Pérez, 2011, p. 56). Por tanto, se convierte en un punto de aplicación y compromiso internacional, donde el DAA hace parte de estas obligaciones internacionales.

\section{Los derechos económicos}

La discusión en términos económicos, se considera en las relaciones con el desarrollo, planteada por Sen, a partir del criterio de que "La capacidad de adquirir alimentos hay que ganársela- en este sentido coloca el problema en una parte de la cadena alimentaria, en el acceso; la posibilidad de acceder a los alimentos depende del- derecho económico de que disfruta cada persona: los bienes sobre los que puede demostrar su propiedad y control. Los individuos padecen hambre cuando no pueden demostrar su derecho económico sobre una cantidad suficiente de alimentos" (Sen, 2000, p. 201 y ss). Sustenta una acción que tiene como base, la ausencia de la capacidad de demostrar su derecho económico y su capacidad de ganárselo, el cual no tiene en cuenta que deben existir acciones integrales sobre el derecho a la alimentación, o lo que se consideró antes como los metaderechos, que justifican cambios de gobierno o exigencias de la población para su aplicación ó a rebelión frente a su ausencia. 
Sen también considera sobre los derechos económicos y su interdependencia, porque:

la desnutrición, la inanición y las hambrunas influye no solo la producción de alimentos y las actividades agrícolas, sino el funcionamiento de la economía y la sociedad. Es fundamental prestar la debida atención a las interdependencias económicas y sociales que rigen la incidencia del hambre en el mundo moderno... las hambrunas pueden prevenirse regenerando las rentas que pierden las posibles víctimas, brindándoles la posibilidad de competir por los alimentos en el mercado, repartiendo de una forma más igualitaria los que hay (Sen, 2000, p. 219 y ss).

En gran medida muestra una crítica a los altos niveles de concentración de la riqueza.

\section{Las obligaciones legales internacionales y las regulaciones constitucionales del DAA}

Las relaciones entre los derechos de las poblaciones, las normas constitucionales y legales y las políticas públicas que se requiere como parte de la solución del problema de SAN y el DAA, por parte del Estado y la sociedad, y que han sido cruzados por la moral y la política; requiere aplicar una serie de compromisos y disposiciones que en el plano internacional buscan resolver estas problemáticas.

La forma como ha evolucionado la reglamentación y discusión del derecho a la alimentación adecuada, se encuentra desde, las declaraciones y encuentros internacionales, hasta las diferentes normas constitucionales, legales y reglamentarias de orden nacional, departamentales y locales. Este entonces, ha quedado explícito de varias maneras, y donde el Estado colombiano asume las responsabilidades como parte de sus acuerdos internacionales.

Diferentes de declaraciones de distinto orden convocan desde un plano internacional a solucionar un problema que afecta la moral global, caso de la ONU que considera:

Es vergonzoso que en un mundo que hoy es más rico que nunca tanta gente tenga que luchar para sobrevivir (...) es inaceptable que más de cinco millones de niños pequeños mueran todos los años a causa de la malnutrición y enfermedades conexas, pero también es inaceptable que cientos de millones de niños no coman lo suficiente para llevar una vida normal, y queden mental y físicamente atrofiados por el resto de sus vidas. El derecho a la alimentación y el derecho a ser protegido contra el hambre son derechos humanos tutelados por el derecho internacional humanitario y de los derechos humanos (ONU, 2005, pág. 5) (Negrilla y subraya fuera de texto) 
Lo cual significa que estos son de obligatorio cumplimiento por parte de los Estados firmantes, los cuales en distintos momentos desde 1948, han venido firmando Acuerdos y pactos con el fin de resolver estas situaciones. En la Tabla número 2 se hace un inventario sobre las declaraciones, compromisos y pactos internacionales conexos o vinculantes con el derecho a la alimentación adecuada para todos los seres humanos.

Estas declaraciones van directamente desde los vínculos con los derechos humanos, hasta las condiciones que permiten construir códigos específicos como el de Sucedáneos de la Leche Materna:

(...) establecer un código para controlar las prácticas inadecuadas de comercialización de sucedáneos ${ }^{7}$ de la leche materna y alimentos infantiles, razón por la cual en 1981 publica el Código Internacional de Comercialización de Sucedáneos de la Leche Materna (CIC), que regula estas actividades en el ámbito mundial (Bogotá, 1998, p. 21).

Tabla 2. Declaraciones, compromisos y pactos internacionales sobre el DAA y sus conexidades

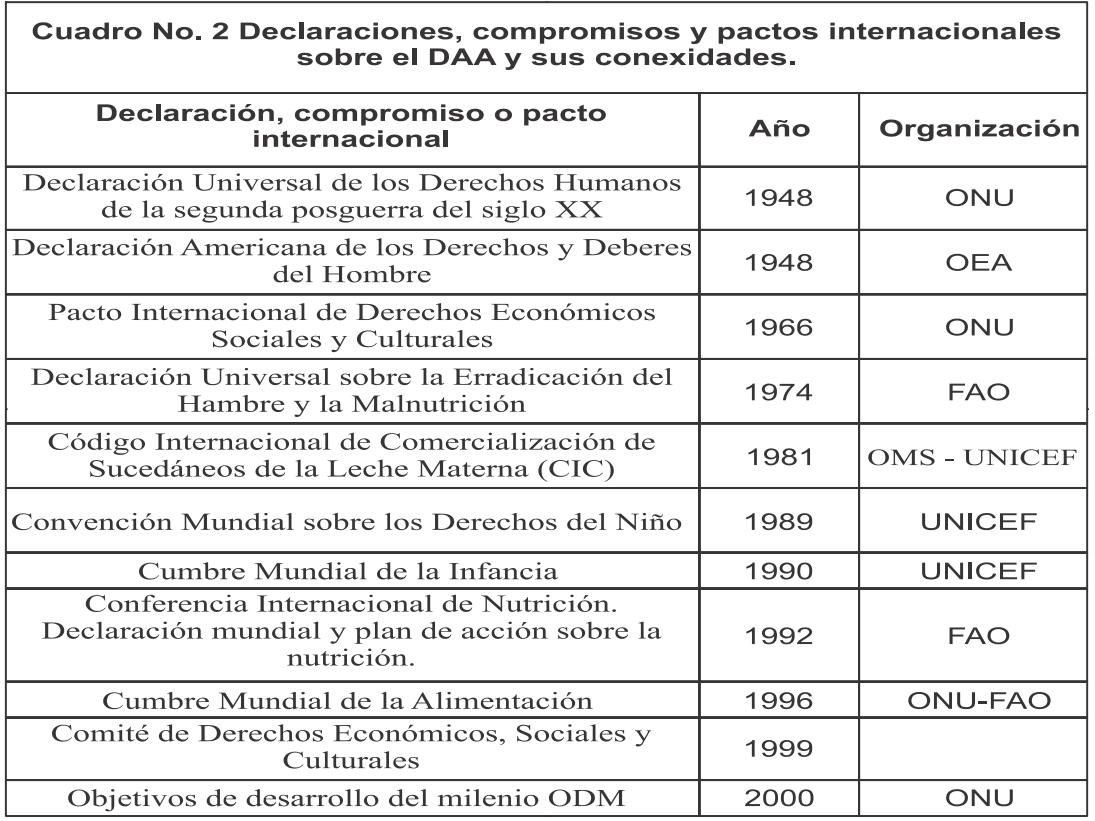

Sucedáneos de la leche materna: todos aquellos productos nacionales o extranjeros, procesados, manufacturados o industrializados, que por sus características, publicidad o promoción comercial, tengan por objeto cumplir total o parcialmente la función de la leche materna en niños o niñas menores de dos años, sean adecuados o no para éste fin. 
También la Observación General número 12 del Comité de Derechos Económicos, Sociales y Culturales, hace una definición del derecho a una alimentación adecuada considerando que este se ejerce "cuando todo hombre, mujer, niño o niña, ya sea solo o en común con otros, tiene acceso físico y económico, en todo momento, a la alimentación adecuada y a los medios para obtenerla” (1999). Bajo estos compromisos se entiende que para poder ejercer este derecho a la alimentación, es necesario tener en cuenta: que en cada país y en cada región interna de este debe tener presente los componentes sobre la alimentación como la disponibilidad, el acceso, las condiciones de la infraestructura y la aceptación cultural por parte de la población.

En cada una de estas obligaciones para el acceso a una alimentación adecuada requiere la orientación, protección y responsabilidad de los Estados no adopten medidas de ningún tipo que tengan por resultado impedir este acceso. En el caso de Colombia y de muchos otros países esta orientación significa que los Estados no deben permitir desalojos de tierras a las comunidades campesinas, indígenas y afrodescendientes, en la medida que estas poblaciones vinculadas a la tierra, pierden el acceso a las tierras fuente de su seguridad alimentaria.

Por otra parte, en el marco del sexagésimo período de sesiones de la ONU, en relación al derecho a la alimentación, el Secretario General anoto, que en un contexto de mundialización se presenta una responsabilidad "para cumplir plenamente sus obligaciones relacionadas con el derecho a la alimentación, las organizaciones internacionales deben respetar, proteger y respaldar el logro del ejercicio del derecho a la alimentación por sus Estados miembros" (ONU, 2005, p. 22), son decisiones imperativas, para los Estados y para las organizaciones globales.

Pogge determina, en relación con los derechos humanos, los compromisos morales y las responsabilidades institucionales así:

(...) la fuerza moral global de los derechos humanos solo se activa por medio de la emergencia de un orden institucional global, hecho que genera la obligación de promover cualesquiera reformas factibles de este orden que mejoren el grado de realización de los derechos humanos (...) Dado que todos los seres humanos participan ahora de un único orden institucional global, todos los derechos humanos por satisfacer se han vuelto, al menos potencialmente, una responsabilidad de todos.

(...) el orden institucional global existente no es un orden natural ni tampoco divino, sino que lo han configurado y lo mantienen los gobiernos más poderosos y otros actores controlados por estos (como la UE, la OTAN, la ONU, la OMC, la OCDE, el Banco Mundial y el FMI). Por lo menos a los ciudadanos 
más privilegiados e influyentes de los países más poderosos y aproximadamente les corresponde una responsabilidad compartida por el papel que desempeñan sus gobiernos en el diseño e imposición de ese orden global, y por el hecho de que dichos gobiernos no contribuyan a reformarlo en la dirección de una mayor realización de los derechos humanos. (Pogge, 2005, p. 218 y ss)

En el caso de América Latina, los diferentes países han vinculado el DAA a través de mecanismos jurídicos, a nivel constitucional, legislativo, normativo y políticas públicas alimentarias nacionales y territoriales. La Tabla 3 muestra una información de las decisiones de los diferentes países latinoamericanos, que han venido diseñando desde sus constituciones, y de sus leyes y decretos sustentando formalmente el DAA. Por otra parte, en algunos casos hay políticas nacionales y territoriales que soportan estas orientaciones nacionales e internacionales, que van desde la creación de programas, fondos, estructuras de organización para la aplicación de la política de orden sistémico, vinculaciones de manejo de seguridad y soberanía alimentaria, relaciones sectoriales, especialmente en salud, educación y agricultura campesina, y manejo de tierras.

Tabla 3. El derecho a la alimentación y la política SAN en América Latina

\begin{tabular}{|c|c|c|c|}
\hline PAís & $\begin{array}{l}\text { DERECHO A LA ALIMENTACIÓN } \\
\text { EN LA CONSTITUCIÓN }\end{array}$ & $\begin{array}{l}\text { LEY DE SEGURIDAD } \\
\text { ALIMENTARIA }\end{array}$ & POLITICA NACIONAL SAN \\
\hline Argentina & $\begin{array}{l}\text { No se menciona, pero el artículo } 75 \\
\text { inciso } 22^{\circ} \text {, se refire al carácter } \\
\text { contitucional de PIDESC. }\end{array}$ & $\begin{array}{l}\text { Ley } 25.724 \text { Plan Nacional de } \\
\text { Seguridad Alimentaria } 2002\end{array}$ & $\begin{array}{l}\text { Programa de emergencia, } \\
\text { politica,asistencia alimentaria - } \\
\text { fondo especial de nutrición y } \\
\text { alimentación nacional - ayuda } \\
\text { alimentaria - desnutrición infantil }\end{array}$ \\
\hline Bolivia & $\begin{array}{l}\text { Se refiere al derecho a la alimentación } \\
\text { en el art. 16, otras menciones en el } \\
\text { art. } 82 \text { y art. } 321 \text { (Constitución en } \\
\text { espera de aprobación ciudadana). }\end{array}$ & $\begin{array}{l}\text { Decreto Supremo } N^{\circ} 1254,13 \text { de } \\
\text { junio de } 2012 \text { ajusta el CONAN. } \\
\text { La ley No } N^{\circ} 622 \text { de Alimentación } \\
\text { Escolar en el Marco del la } \\
\text { Soberanía Alimentaria y la } \\
\text { Economía Plural - } 2015\end{array}$ & $\begin{array}{l}\text { Decreto Supremo } N^{\circ} 2167,30 \text { de } \\
\text { octubre de } 2014 \text {. Política de } \\
\text { Alimentación y Nutrición }\end{array}$ \\
\hline Brasil & $\begin{array}{l}\text { Menciona derecho de los trabajadores } \\
\text { a ser atendidos por su empleador en } \\
\text { alimentación (art. 7), alimentación } \\
\text { escolar (art. 208 y 212) y como deber } \\
\text { de las familias, el Estado y la sociedad } \\
\text { alimentar a los niños (art. 2277) y a la } \\
\text { salud y maternidad (art. 6). }\end{array}$ & $\begin{array}{l}\text { Ley orgánica de seguridad } \\
\text { alimentaria y nutricional } \\
\text { aprobada en } 2006 .\end{array}$ & $\begin{array}{l}\text { Documento final de la III } \\
\text { Conferencia de SAN y el Programa } \\
\text { Hambre Cero. Decreto 7.272, de } \\
\text { 2010: crea la Política Nacional de } \\
\text { Seguridad Alimentaria y Nutricional } \\
\text { y el Plan Nacional de Seguridad } \\
\text { Alimentaria y Nutricional }\end{array}$ \\
\hline Chile & $\begin{array}{c}\text { No se menciona, pero hace referencia } \\
\text { al derecho a la salud y a la seguridad } \\
\text { social (art. 19) }\end{array}$ & No existe un proyecto de Ley & $\begin{array}{l}\text { Sin politica especifica de SAN, } \\
\text { pero semenciona en Plan Nacional } \\
\text { de Salud }\end{array}$ \\
\hline Colombia & $\begin{array}{l}\text { Se refiere a un nivel de vida adecuado } \\
\text { (art. } 44,46,47,48,49 \text { y y derecho a } \\
\text { la alimentación de los niños (art. } 44) \text {. }\end{array}$ & $\begin{array}{c}\text { Proyecto de Ley de Seguridad } \\
\text { alimentaria y nutricional en } \\
\text { discusión para aprobación } \\
\text { enero } 2015 .\end{array}$ & $\begin{array}{l}\text { Sistema Nacional de Seguridad } \\
\text { Alimentaria y Nutricional Agencia } \\
\text { Nacional de Seguridad } \\
\text { Alimentaria y Nutricional }\end{array}$ \\
\hline Costa Rica & $\begin{array}{l}\text { No se menciona, pero si la superioridad } \\
\text { de los tratados internacionales } \\
\text { ratificados por la Asamble Legislativa, } \\
\text { como el caso del PIDESC (art. 6) }\end{array}$ & $\begin{array}{l}\text { Proyecto de Ley marco SAN } \\
\text { en discusión desde } 2004 \text {. }\end{array}$ & $\begin{array}{c}\text { Plan Nacional de Salud 2010-2021, } \\
\text { promueve la seguridad alimentaria } \\
\text { y nutricional también en la Política } \\
\text { de Estado, para el Sector } \\
\text { Agroalimentario y el Desarrollo } \\
\text { Rural 2010-2021 }\end{array}$ \\
\hline
\end{tabular}




\begin{tabular}{|c|c|c|c|}
\hline PAís & $\begin{array}{l}\text { DERECHO A LA ALIMENTACIÓN } \\
\text { EN LA CONSTITUCIÓN }\end{array}$ & $\begin{array}{l}\text { LEY DE SEGURIDAD } \\
\text { ALIMENTARIA }\end{array}$ & POLITICA NACIONAL SAN \\
\hline Cuba & $\begin{array}{l}\text { Se refiere al derecho del niño a } \\
\text { alimentarse (art. 9), además a la } \\
\text { seguridad social (art 48). }\end{array}$ & No existe un proyecto de Ley & Sin una politica especifica SAN. \\
\hline Ecuador & $\begin{array}{l}\text { Se refiere al derecho a alimentación } \\
\text { (art. } 3 \text { y } 66 \text { ), además se lo menciona } \\
\text { en otros artículos (art. } 32 \text { y 69). }\end{array}$ & $\begin{array}{l}\text { Ley de soberania y seguridad } \\
\text { alimentaria y nutricional } 2009 .\end{array}$ & \begin{tabular}{|c|} 
Declaración seguridad alimentaria y \\
nutricional como política de Estado \\
2008 . \\
\end{tabular} \\
\hline El Salvador & $\begin{array}{c}\text { No se menciona pero hace referencia } \\
\text { al derecho de los trabajadores, } \\
\text { seguridad social y salud } \\
\text { (art. } 35,37,38,66,69,70,101)\end{array}$ & $\begin{array}{l}\text { En discusión propuesta de ley } \\
\text { de soberanía y seguridad } \\
\text { alimentaria y nutricional }\end{array}$ & $\begin{array}{l}\text { Política nacional SAN 2003, } \\
\quad \text { Plan SAN 2006. }\end{array}$ \\
\hline Guatemala & $\begin{array}{l}\text { Se mencioan (art. 99) y la proteccion } \\
\text { de los niños y ancianos (art. 51). }\end{array}$ & $\begin{array}{c}\text { Ley marco de seguridad y/o } \\
\text { soberanía alimentariaaprobada } \\
\text { en } 2005\end{array}$ & Plan Estratégico SAN 2007-2016 \\
\hline Honduras & \begin{tabular}{|c|} 
Señala que el Poder Ejecutivo fomentará \\
programas para mejorar el estado \\
nutricional de la población (art. 150) y \\
menciona el derecho a la alimentación \\
de los niños, otrogandoles la \\
responsabilidad a los padres (art. 121).
\end{tabular} & \begin{tabular}{|c|} 
Ley marco de seguridad y/o \\
soberania alimentaria 2011. Crea \\
el Sistema Nacional de Seguridad \\
Alimentaria y Nutricional
\end{tabular} & $\begin{array}{c}\text { Estrategia Nacional de Seguridad } \\
\text { Alimentaria y Nutricional. Politica } \\
\text { SAN de Estado de Prioridad } \\
\text { Nacional } 2011\end{array}$ \\
\hline México & $\begin{array}{c}\text { Se refiere al derecho a la alimentación } \\
\text { de los niños (art. 4) y a la seguridad } \\
\text { social (art. 123). }\end{array}$ & $\begin{array}{c}\text { seguridad y soberania } \\
\text { agroalimentaria y nutricional } 2005, \\
\text { Ley seguridad alimentaria y } \\
\text { nutricional, México D.F. } 2009\end{array}$ & $\begin{array}{l}\text { Sin política especifica SAN, } \\
\text { pero se menciona en la Política } \\
\text { de Desarrollo Social 2007-2012 }\end{array}$ \\
\hline Nicaragua & $\begin{array}{l}\text { Se refiere al derecho a la alimentación } \\
\text { (art. 63). }\end{array}$ & $\begin{array}{l}\text { Ley de soberanía y seguridad } \\
\text { alimentaria } 2009 .\end{array}$ & $\begin{array}{c}\text { Sistema Nacional de Soberania y } \\
\text { Seguridad Alimentaria y Nutricional } \\
\text { Política Nacional de Soberanía y } \\
\text { Seguridad Alimentaria y Nutricional } \\
\text { con equidad de género y étnica. } \\
2009 \\
\end{array}$ \\
\hline Panama & $\begin{array}{l}\text { Se refiere a la responsabilidad del } \\
\text { Estado de proteger el estado nutricional } \\
\text { de la población (art. 110). }\end{array}$ & $\begin{array}{c}\text { Ley del sistema de seguridad } \\
\text { alimentaria y nutricional desde } 2005 \text {. }\end{array}$ & $\begin{array}{l}\text { Plan Nacional de Seguridad } \\
\text { Alimentaria y Nutricional } \\
\text { para 2009-2015. }\end{array}$ \\
\hline Paraguay & $\begin{array}{l}\text { No se menciona, pero se refiere a la } \\
\text { responsabilidad de los padres de } \\
\text { alimentar a los niños (art. 53) y a la } \\
\text { seguridad social (art. 95). }\end{array}$ & \begin{tabular}{|c|} 
Ley Marco de Soberanía, \\
Seguridad Alimentaria y Nutricional \\
y Derecho a la Alimentación. 2013
\end{tabular} & $\begin{array}{c}\text { Plan Nacional De Soberania y } \\
\text { Seguridad Alimentaria y Nutricional } \\
\text { del Paraguay PLANAL 2009 Sin una } \\
\text { pólitica especifica SAN, pero se } \\
\text { menciona en la Política Nacional de } \\
\text { Salud 2005-2008 y en el Plan } \\
\text { Agrario Rural 2004-2008. }\end{array}$ \\
\hline Peru & $\begin{array}{c}\text { No se menciona, pero se refiere a la } \\
\text { integridad fisica de los niños, a la } \\
\text { seguridad social (art. } 4,10,11,24)\end{array}$ & $\begin{array}{l}\text { Decreto Supremo } \\
\text { 021-2013-MINAGRI. }\end{array}$ & $\begin{array}{l}\text { Estrategia Nacional de Seguridad } \\
\text { Alimentaria y Nutricional 2013-2021 }\end{array}$ \\
\hline $\begin{array}{l}\text { Republica } \\
\text { Dominicana }\end{array}$ & $\begin{array}{l}\text { No se menciona pero se refiere a la } \\
\text { responsabilidad del Estado de mejorar } \\
\text { la alimentación de para los habitantes } \\
\text { (art. 8). }\end{array}$ & $\begin{array}{l}\text { Proyecto de ley que asegura el } \\
\text { sistema nacional de seguridad } \\
\text { alimentaria en discusión } \\
\text { desde } 2007 \text {. }\end{array}$ & $\begin{array}{l}\text { Sin una politica especifica SAN, } \\
\text { pero si se menciona en el Plan } \\
\text { Estratégico de Salud 2008-2009. }\end{array}$ \\
\hline Uruguay & $\begin{array}{l}\text { No se menciona, pero se refiere al } \\
\text { derecho a la salud (art. } 44 \text { y } 46 \text { ) } \\
\text { y a seguro social (art. 67) }\end{array}$ & $\begin{array}{c}2014 \text { de la Ley } 19.140 \text { sobre } \\
\text { alimentación saludable en centros } \\
\text { educativos }\end{array}$ & $\begin{array}{l}\text { Sin una politica SAN especifica pero } \\
\text { si se menciona en el Plan Equidad } \\
2007 \text {. Ley } N^{\circ} 18.832 \text { Unidad } \\
\text { Alimentaria de Montevideo } \\
\end{array}$ \\
\hline Venezuela & $\begin{array}{l}\text { La obligación SAN se menciona } \\
\text { (art. 305). }\end{array}$ & $\begin{array}{c}\text { Ley Organica de Seguridad y } \\
\text { Soberania Alimentaria aprobada } \\
2008 \text { Ley de Reforma Parcial de } \\
\text { la Ley de Tierras y Desarrollo } \\
\text { Agrario } 2010\end{array}$ & $\begin{array}{l}\text { Estrategia nacional SAN 2004. Plan } \\
\text { Integral de Desarrollo Agrícola } 2007\end{array}$ \\
\hline \multicolumn{4}{|c|}{$\begin{array}{l}\text { Fuente: VIVERO José Luis y RAMIREZ Pablo 2009. "Leyes, políticas e instituciones contra el hambre en el contexto latinoamericano" } \\
\text { Publicado en: Derecho a a Alimentación Políticas Públicas e Instituciones contra el Hambre. Editores José Luis Vivero y Ximena Erazo. } \\
\text { LOM Ediciones, Fundación Henry Dunant América Latina DESC y Políticas Públicas, Iniciativa América Latina Sin Hambre. Santiago de } \\
\text { Chile. Pág. 169. Actualizada en varios paises para esta ponencia sobre DAA por el autor. }\end{array}$} \\
\hline
\end{tabular}

Las condiciones que se presentan en América Latina frente al problema del hambre y la desnutrición, se expresan en la Tabla 4, donde se ven los millones de personas en condiciones de subalimentación, y que en 24 años se disminuyeron en 31.5 millones. Y las 37 que quedan en este estado de hambre y subalimentación, ¿cuántos años requieren de acciones para llegar a los programas que en distintos países y territorios se plantean como hambre cero? Se requerirá, al ritmo que se resolvieron hasta hoy, otro cuarto de siglo para su solución. Uno de los países con mayores niveles de población con hambre es Colombia, seguido de Haití. 
Tabla 4. Número (millones de personas) y prevalencia (\&) del hambre en América Latina y el Caribe, 1990-1992 a 2012-2014.

\begin{tabular}{|c|c|c|c|c|c|c|c|c|}
\hline \multicolumn{9}{|c|}{$\begin{array}{l}\text { Cuadro No. 4. Número (millones de personas) y prevalencia (\%) del hambre } \\
\text { en América Latina y el Caribe, } 1990-92 \text { a } 2012-2014 \text {. }\end{array}$} \\
\hline & \multicolumn{4}{|c|}{ Millones de personas } & \multicolumn{4}{|c|}{ Prevalencia de la subalimentacion } \\
\hline Pais & $1990-92$ & $2000-02$ & $2009-11$ & $2012-14$ & $1990-92$ & $2000-02$ & $2009-11$ & $2012-14$ \\
\hline Argentina & $n s$ & $\mathrm{~ns}$ & ns & ns & $<5$ & $<5$ & $<5$ & $<5$ \\
\hline Barbados & ns & 0 & ns & ns & $<5$ & 5.2 & $<5$ & $<5$ \\
\hline Belice & 0 & $\mathrm{o}$ & 0 & $\mathrm{o}$ & 9,7 & 5,9 & 5,9 & 6,5 \\
\hline Bolivia & 2,6 & 2,8 & 2,7 & 2,1 & 38 & 32,8 & $\frac{2,3}{26,9}$ & 19,5 \\
\hline Brasil & 22,5 & 29 & ns & ns & 14,8 & 10,7 & $<5$ & $<5$ \\
\hline Chile & 1,2 & ns & ns & ns & 9 & $<5$ & $<5$ & $<5$ \\
\hline Colombia & 7,3 & 5,4 & 7,1 & 5,5 & 21,6 & 13,4 & 15,3 & 11,4 \\
\hline Costa Rica & 0,2 & 0,2 & 0,2 & 0.3 & 5,2 & 5,1 & 5,3 & 5,9 \\
\hline Cuba & 0,6 & ns & $\mathrm{ns}$ & ns & 5,7 & $<5$ & $<5$ & $<5$ \\
\hline Ecuador & 2 & 2,4 & 2,1 & 1,8 & 19,4 & 18,6 & 14,2 & 11,2 \\
\hline El Salvador & 0,9 & 0,6 & 0,7 & 0,9 & 16,2 & 10,6 & 12 & 13,5 \\
\hline Guatemala & 1,4 & 2,3 & 2,1 & 2,2 & 14,9 & 20,2 & 14,7 & 14,3 \\
\hline Guyana & 0.2 & 0,1 & 0,1 & 0.1 & 22.8 & 9,7 & 11,9 & 10 \\
\hline Haití & 4,4 & 4,8 & 5 & 5,3 & 61,1 & 55,2 & 50,5 & 51,8 \\
\hline Honduras & $\frac{4,4}{1,2}$ & $\frac{4,8}{1,2}$ & $\frac{5}{1,1}$ & $\frac{3,3}{1}$ & $\frac{81,1}{23}$ & $\frac{53,2}{18,5}$ & $\frac{50,5}{14,9}$ & $\frac{3,8}{12,1}$ \\
\hline Jamaica & 0,2 & 0,2 & 0,2 & 0,2 & 10,4 & 7,3 & 7,9 & 7,9 \\
\hline México & $\frac{0,2}{6}$ & $\mathrm{~ns}$ & $\mathrm{~ns}$ & ns & 6,9 & $<5$ & $<5$ & $<<5$ \\
\hline Nicaragua & 2,3 & 1,6 & 1,2 & 1 & 54,4 & 31,3 & 20,3 & 16,8 \\
\hline Panamá & 0.7 & 0,9 & 0,5 & 0,4 & 26,4 & 27,6 & 14,8 & 10,6 \\
\hline Paraguay & 0,9 & 0,7 & 0,7 & 0,7 & 19,5 & 12,9 & 10,4 & 11 \\
\hline Perú & 7 & 5,4 & 3,6 & 2,7 & 31,6 & 20,6 & 12,3 & 8,7 \\
\hline $\begin{array}{c}\text { Republica } \\
\text { Dominicana }\end{array}$ & 2.5 & 2,5 & 1,8 & 1.5 & 34,4 & 28.5 & 18,2 & 14,7 \\
\hline $\begin{array}{c}\text { San Vicente } \\
\text { y las } \\
\text { Granadinas }\end{array}$ & o & o & o & o & 20,7 & 16,8 & 6,8 & 5,7 \\
\hline Surinam & 0,1 & 0,1 & o & 0 & 15,5 & 13,9 & 8,7 & 8,4 \\
\hline $\begin{array}{c}\text { Trinidad y } \\
\text { Tobágo }\end{array}$ & $\mathrm{Ol}, 2$ & 0.2 & 0.1 & 0.1 & 12,6 & 11,9 & 10,2 & 9 \\
\hline Uruguay & 0,3 & ns & ns & ns & 8,5 & $<5$ & $<5$ & $<5$ \\
\hline Venezuela & 2,8 & 3,8 & ns & ns & $\frac{0,0}{14,1}$ & 15,4 & $<5$ & $<5$ \\
\hline $\begin{array}{l}\text { AMÉRICA } \\
\text { LATINA }\end{array}$ & 60,3 & 52,7 & 33,9 & 29,5 & 14,4 & 10,7 & 6,1 & 5,1 \\
\hline CARIBE & 8,1 & 8,2 & 7,6 & 7,5 & 27 & 24,4 & 20,7 & 20,1 \\
\hline $\begin{array}{l}\text { AMÉRICA } \\
\text { LATINA Y EL } \\
\text { CARIBE }\end{array}$ & 68,5 & 61 & 41,5 & 37 & 15,3 & 11,5 & 7 & 6,1 \\
\hline
\end{tabular}

\section{La situación en Colombia}

En Colombia se ha venido generando una legislación que pretende, desde la Constitución de 1991, darle un cuerpo jurídico al derecho a la alimentación de manera amplia (Gómez, 2006) ${ }^{8}$. En este punto solo hacemos un pequeño comentario sobre su aplicación en el país, de manera general.

Por ejemplo, en la Constitución de 1991 se consideró este derecho en el Capítulo 2, "De los derechos sociales, económicos y culturales", los cuales se consideran derechos de segunda generación y en su artículo 65 dice: "La producción de alimentos gozará de especial protección del Estado (...) de igual manera el Estado promoverá la investigación y transferencia de tecnología para la producción de alimentos"; en esta dirección la constitución determinaba los criterios sobre los cuales se debían orientar

$8 \quad$ Este trabajo, promovido por la Defensoría del Pueblo, es el que mejor da cuenta de estas normas de carácter nacional y su respectiva jurisprudencia; tanto en la metodología, las obligaciones generales, de efecto inmediato y de cumplimiento progresivo; las condiciones del derecho a la alimentación a través de la cadena alimentaria con la disponibilidad, el acceso y el uso biológico. 
las políticas en función de una disponibilidad nacional de alimentos.

En el capítulo III "Sobre los derechos colectivos y del ambiente", la Constitución Política determina en el artículo 78: "La ley regulará el control de calidad de bienes y servicios ofrecidos y prestados a la comunidad, así como la información que debe suministrarse al público en su comercialización. Serán responsables, de acuerdo con la ley, quienes en la producción y en la comercialización de bienes y servicios, atenten contra la salud, la seguridad y el adecuado aprovisionamiento a consumidores y usuarios". Lo cual sugiere un principio central que tiene que ver con el derecho a la salud.

En el caso colombiano, dados los niveles del conflicto, en particular en los procesos de desplazamiento rural, es necesario tener en cuenta que la obligación de respetar el acceso a alimentación en las zonas rurales, además de resolver la situación del hambre y en particular sus condiciones críticas, las cuales según la FAO (citada por Monsalve, 2004), en el mundo rural

cerca del $80 \%$ de las personas que han padecido hambre o desnutrición en todo el mundo vive en zonas rurales. Los pequeños y las pequeñas agricultoras en tierras marginales, las familias sin tierra y los jornaleros y jornaleras constituyen los grupos sociales más afectados por el hambre en el mundo entero (...) Garantizar el acceso a los recursos productivos como la tierra para que las personas puedan realizar plenamente su derecho a alimentarse es un asunto que obviamente requiere recursos. (Monsalve, 2004, p. 49)

Y en estas condiciones, el derecho a la tierra, a pesar de sus restricciones, se vincula sustancialmente en conexidad, por tanto, "la literatura que se ocupa de este tema es que no toca de manera explícita la cuestión de un 'derecho humano a la tierra', sino que se usan vías indirectas para abordarlo" (Herreño, 2004, p. 250), como "los derechos a la tierra", los "derechos humanos relacionados con la tierra" o los "derechos de propiedad" o "a la propiedad" de la tierra. 
Tabla 5. Colombia. Los obligados y las obligaciones en la realización del derecho a la alimentación

\begin{tabular}{|c|c|c|c|}
\hline \multicolumn{4}{|c|}{$\begin{array}{r}\text { Cuadro } 5 \text { Colombia. Los obligados y las obligaciones en la realización } \\
\text { del derecho a la alimentación }\end{array}$} \\
\hline \multicolumn{4}{|c|}{ 吾 } \\
\hline 1. La Familia & 2. La Sociedad & $\begin{array}{l}\text { 3. Empresas } \\
\text { Transnacionales y otras } \\
\text { Empresas Comerciales }\end{array}$ & $\begin{array}{l}\text { 4. Instituciones } \\
\text { Internacionales }\end{array}$ \\
\hline \multicolumn{4}{|c|}{ 5. Estado } \\
\hline \multicolumn{4}{|c|}{ 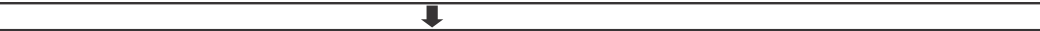 } \\
\hline \multirow{7}{*}{$\begin{array}{c}5.1 \\
\text { Obligaciones } \\
\text { sobre la } \\
\text { cadena } \\
\text { alimentaria }\end{array}$} & \multirow{7}{*}{$\begin{array}{l}5.2 \\
\text { Obligaciones } \\
\text { de respeto, } \\
\text { protección y } \\
\text { realización }\end{array}$} & $\begin{array}{l}5.3 \text { Obligaciones de Efecto } \\
\text { Inmediato }\end{array}$ & $\begin{array}{l}5.4 \text { Obligaciones de } \\
\text { Cumplimiento } \\
\text { Progresivo }\end{array}$ \\
\hline & & 7 & $\sqrt{1}$ \\
\hline & & $\begin{array}{l}\text { Medidas: legislativas, } \\
\text { judiciales, presupuestales, } \\
\text { administrativas, educativas }\end{array}$ & \multirow{5}{*}{$\begin{array}{c}\text { Mecanismos para } \\
\text { observar el derecho } \\
\text { a la alimentación } \\
\text { nacional e } \\
\text { internacional }\end{array}$} \\
\hline & & Estrategias y programas & \\
\hline & & $\begin{array}{c}\text { Garantizar la no } \\
\text { discriminación }\end{array}$ & \\
\hline & & $\begin{array}{l}\text { No adoptar medidas } \\
\text { regresivas }\end{array}$ & \\
\hline & & $\begin{array}{l}\text { Vigilar el grado de } \\
\text { realización }\end{array}$ & \\
\hline
\end{tabular}

\section{El círculo vicioso del derecho a la alimentación}

Frente al desarrollo de este derecho en Colombia, encontramos lo que se llama el círculo vicioso del derecho a la alimentación, el cual se presenta en la medida que las poblaciones afectadas por hambre física, son las que estructuralmente padecen de la ausencia de claras políticas públicas sociales y de los mecanismos de redistribución de ingresos, que llevan a un círculo vicioso de pobreza-hambre-malnutriciónenfermedad. Situación que exige políticas públicas de diferente orden, que estén en función de atacar dicho circulo-problema, que en la medida en que sean focalizadas no resuelven el problema de forma estructural, sino coyuntural, y en esta dirección combinan las políticas sociales que promuevan el acceso a los alimentos y salud con diversas intervenciones internacionales, nacionales y subnacionales.

Sin embargo, las intervenciones, en la medida que llegan tarde, generan otros problemas vinculados con la falta de una alimentación adecuada; como son las enfermedades estructurales para el resto de la vida. Por consiguiente, son enfermedades que no tienen reversa, como observa la FAO:

Casi una tercera parte del total de los niños de los países en desarrollo sufre un retraso del crecimiento y su estatura es muy inferior al promedio normal de los niños de su edad, lo que indica una subnutrición crónica. El retraso del crecimiento, al igual que el bajo peso al nacer, ha sido asociado a una mayor incidencia de enfermedades y fallecimientos, así como a una capacidad cognitiva más reducida, a una menor asistencia escolar durante la infancia y a una menor 
productividad e ingresos más bajos a lo largo de la vida en la etapa adulta. Cuando se produce un retraso del crecimiento durante los cinco primeros años de vida, los daños en el desarrollo físico y cognitivo del niño suelen ser irreversibles (FAO, 2004, p. 8).

Estas implicaciones para el resto de vida de los individuos y para la sociedad, son graves, y en este punto estructural de los seres humanos se traslada el problema para atenderse a través de la salud pública, pues este daño por desnutrición en estas edades no tiene reparación.

Esto último presenta una incoherencia grave de la política pública, porque aunque allí se busquen soluciones, a veces estas se presentan como paliativo, por tanto, es mejor implementar las políticas públicas al inicio del ciclo, cuando se puedan prevenir las acciones de curación, de tal forma que es en la prevención, coordinación y una visión integral, con que el Estado debe cumplir con el derecho a la alimentación.

Por consiguiente, las repercusiones del hambre y la malnutrición sobre el ciclo de vida, deben tener presente que las acciones han de pasar por vincular el derecho a la alimentación, integrado al de la salud; los cuales, a su vez, vinculan la política social de salud pública, de base preventiva, eje de la salud. En este sentido, aplicar estos derechos permite que las personas tengan acceso siempre a los alimentos para llevar una vida saludable y activa; ya que se encuentra que hoy "se acepta ampliamente que la malnutrición en los países en desarrollo se debe al consumo insuficiente de proteínas y energía, que a menudo se asocia con enfermedades infecciosas" (Latham, 2002, pág. 16). Lo cual sugiere que las políticas públicas en esta dirección deben ir en la dinámica de superar las acciones sobre hambre física, para integrarse también a nutrición y salud.

\section{Conclusiones}

- Las condiciones estructurales de orden económico y social se continúan agravando a pesar de los esfuerzos realizados por los gobiernos y algunas instituciones globales a través de políticas públicas que buscan hacer cumplir el derecho a la alimentación. Sin embargo, esta situación no se va a resolver si no se realizan reformas de fondo sobre los elementos estructurales de las condiciones económicas sociales y culturales, presentes en todos los países, no obstante la caracterización diferencial de las situaciones de desnutrición presentes en cada uno.

- Aunque hay un reconocimiento jurídico y normativo de diferente nivel, sobre el derecho fundamental a la alimentación, como parte del derecho a la vida, este principio es violado de manera recurrente por los responsables de hacerlo cumplir.

- Pese a que las condiciones nacionales en América Latina presentan las mismas dinámicas globales; por una parte, la concentración y centralización económica, 
y por otra, las reglamentaciones sobre el derecho a la alimentación, la situación mejora de forma marginal.

- En el caso colombiano, las políticas y los derechos se integran formalmente, pero la realidad va por otro lado, y lo que es más grave, las muertes por desnutrición en comunidades indígenas, especialmente de población infantil, son la punta del iceberg en que se encuentra la población colombiana frente al derecho a la alimentación.

\section{Referencias}

Arango, R. (2005). El concepto de los derechos sociales fundamentales. Bogotá: Universidad Nacional de Colombia y Legis.

Arango, R. \& Lemaitre, J. (2002). Jurisprudencia constitucional sobre el derecho al mínimo vital. Bogotá: Universidad de los Andes, Facultad de Derecho, Centro de Investigaciones Sociojurídicas -CIJUS-.

Aplicación del Pacto Internacional de los Derechos Económicos, Sociales y Culturales, Observación general 12, El derecho a una alimentación adecuada (art. 11), (20º período de sesiones, 1999), U.N. Doc. E/C.12/1999/5 (1999).

De Sousa Santos, B. (1998). La globalización del derecho los nuevos caminos de la regulación y las emancipación. Bogotá: Universidad Nacional de Colombia, Facultad de Derecho, Ciencias Políticas y Sociales, Instituto Latinoamericano de Servicios legales Alternativos, ILSA.

Caetano G. \& De Armas, G. (2015, 30 de marzo). Pobreza y desigualdad en América Latina (1980-2014). El País de Madrid.

Cepal \& Celade Observatorio Demográfico. (2013). América Latina y el Caribe. Ciudad Chile. Editorial Celade

Cepal. (2014). Panorama social de América Latina. Ciudad Chile. Editorial Celade

Cepal. (2002). Vigesimonoveno período de sesiones Brasilia. Globalización y desarrollo. Brasil 6 al 10 de mayo de 2002.

Gómez, M. P. (2006). El derecho a la alimentación en la Constitución, la jurisprudencia y los instrumentos internacionales. Bogotá: Defensoría del Pueblo-Prosedher. Serie DESC.

Habermas, J. (1998). Facticidad y validez sobre el derecho y el Estado democrático de derecho en términos de teoría del discurso. Madrid: Trotta.

Hauenstein, S. \& Vaitla, B. (2007). El hambre injusta. Una crónica reciente de la lucha por los alimentos y la dignidad. Hunger Watch informe 2007-2008. Barcelona: Icaria. 
Herreño, A. L. (2004). Evolución política y legal del concepto de territorio ancestral indígena en Colombia. En El otro derecho. Derecho a la tierra, conceptos, experiencias y desafíos (31-32). Bogotá: ILSA Instituto Latinoamericano de Servicios Sociales Alternativos, Ediciones Antropos.

Latham, M. C. (2002). Nutrición humana en el mundo en desarrollo. Roma: FAO.

Medina, J. M. (2006). La lucha contra el hambre desde el enfoque de los DESC. En Seminario Seguridad Alimentaria y Lucha contra el hambre. CEHAPUniversidad de Córdoba.

Meyers, D. T. (1988). Los derechos inalienables. Madrid: Alianza Universidad.

Molina, A. (2005). El derecho humano al agua en la Constitución, la jurisprudencia y los instrumentos internacionales. Serie estudios especiales DESC. Bogotá: Defensoría del Pueblo Colombia.

Monsalve, S. (2004). Derecho a la tierra y derechos humanos. En El otro derecho. Derecho a la tierra Conceptos, experiencias y desafios (pp. 31-32). Bogotá: ILSA Instituto Latinoamericano de Servicios Sociales Alternativos, Ediciones Antropos

Monsalve, S. (2007). Acceso a la tierra y los recursos productivos. Hacia una interpretación sistemática de las directrices voluntarias de la FAO sobre el derecho a la alimentación. FIAN Internacional FIAN Informe R 1 Informes.

ONU. (2005, 30 de sep.). El Derecho a la Alimentación. Nota del Secretario General. Documento A/60/30.

ONU-Hábitat (2012). Programa de las Naciones Unidas para los Asentamientos Humanos. Estado de las ciudades de América Latina y el Caribe 2012. Rumbo a una nueva transición urbana.

Pérez, F. (2011). El derecho fundamental a la alimentación básica. Bogotá: Universidad Externado de Colombia.

Plan de Alimentación y Nutrición del Distrito Capital, 1999-2003. Un Plan con Viabilidad Local.

Pogge, T. (2005). La pobreza en el mundo y los derechos humanos. Barcelona: Paidós.

Sen, A. K. (2000). Desarrollo y libertad. Bogotá: Planeta.

Sen, A. K. (2002). El derecho a no tener hambre. Bogotá: Universidad Externado de Colombia, Centro de investigación en Filosofía y Derecho.

Vernon, J. (2011). El hambre, una historia moderna. Valencia, España: Publicaciones de la Univeritat de Valéncia. 